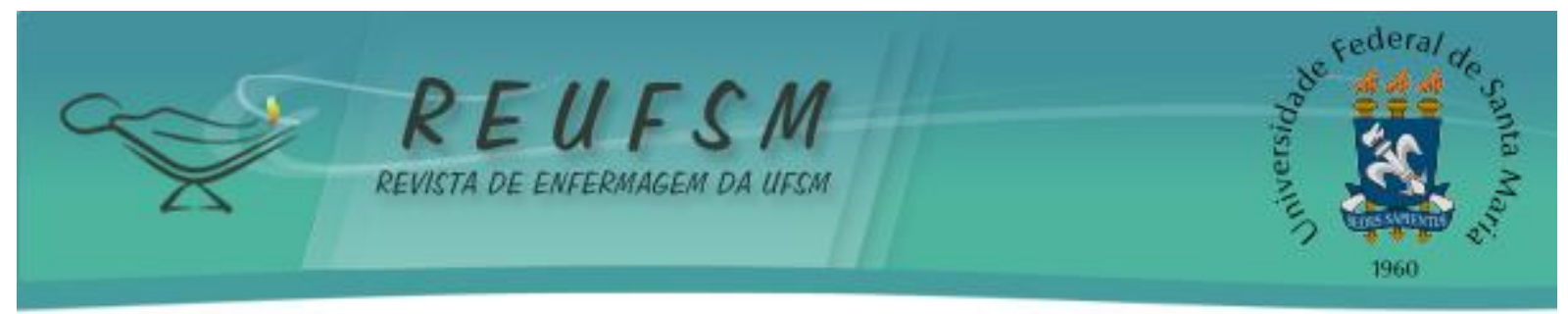

ARTIGO ORIGINAL

\title{
A FAMÍLIA FRENTE AO ADOECIMENTO POR CÂNCER DE MAMA
} THE FAMILY BEFORE TO ILLNESS FROM BREAST CANCER

\section{LA FAMILIA FRENTE A LA ENFERMEDAD DE CÁNCER DE MAMA}

\author{
Nara Marilene Oliveira Girardon-Perlini ${ }^{1}$ \\ Jane Maria Hoffmann ${ }^{2}$ \\ Danusa Begnini ${ }^{3}$ \\ Claudelí Mistura ${ }^{4}$ \\ Bruna Stamm ${ }^{5}$
}

Doi: $10.5902 / 2179769220893$

RESUMO: Objetivo: compreender a participação da família no decorrer da trajetória do adoecimento por câncer de mama. Método: estudo descritivo, de abordagem qualitativa, realizado com sete pessoas integrantes de duas famílias que vivenciaram o adoecimento por câncer de mama. 0 instrumento de coleta de dados foi uma entrevista semiestruturada. A análise de conteúdo temática foi utilizada para 0 tratamento e análise de dados, tendo como referencial teórico o Modelo de Constelação da Doença. Resultados: os dados foram organizados em quatro categorias: estágio da incerteza, estágio da ruptura, esforçando-se para recuperar o self e recuperando o bem estar. Considerações finais: o estudo possibilitou ampliar o conhecimento e a compreensão acerca da participação da família diante do adoecimento por câncer de mama com base em um modelo teórico específico.

Descritores: Família; Neoplasias; Doença crônica; Enfermagem; Neoplasias da mama.

ABSTRACT: Aim: to understand the participation of the family during the illness trajectory for breast cancer. Method: a descriptive study of qualitative approach, carried out with seven members of two families who suffered the disease of breast cancer. The data collection occurred through a semi-structured interview. The thematic content analysis was used to conduct and analyse data from the theoretical Framework of the Disease Constellation Model. Results: data were organized into four categories: the uncertainty stage, rupture stage, struggling to regain self and recovering well being. Final thoughts: the study enabled the expansion of the knowledge and understanding of family participation before the illness from breast cancer based on a specific theoretical model.

Descriptors: Family; Neoplasms; Chronic disease; Nursing; Breast neoplasms.

\footnotetext{
${ }^{1}$ Enfermeira. Doutora em Enfermagem. Professora Adjunta do Departamento de Enfermagem e do Programa de Pós-Graduação em Enfermagem da Universidade Federal de Santa Maria(UFSM). Santa Maria, RS. Brasil. E-mail: nara.girardon@gmail.com.

2 Enfermeira. Especialista em Saúde da Família. Secretaria Municipal da Saúde de Ijuí/RS. Ijuí, RS, Brasil. Email: jhenf1@hotmail.com

${ }^{3}$ Enfermeira. Mestre em Enfermagem. Professora Substituta na Universidade Federal de Santa Maria (UFSM), Campus de Palmeira das Missões, RS, Brasil. E-mail: danusabegnin@hotmail.com

${ }^{4}$ Enfermeira. Mestre em Enfermagem. Professora da Universidade de Cruz Alta (UNICRUZ). Cruz Alta, RS, Brasil. E-mail: claumistura@gmail.com

${ }^{5}$ Enfermeira. Mestre em Enfermagem. Professora Assistente na Universidade Federal do Pampa (UNIPAMPA). Uruguaiana, RS. Brasil. E-mail: brunastamm@hotmail.com
} 


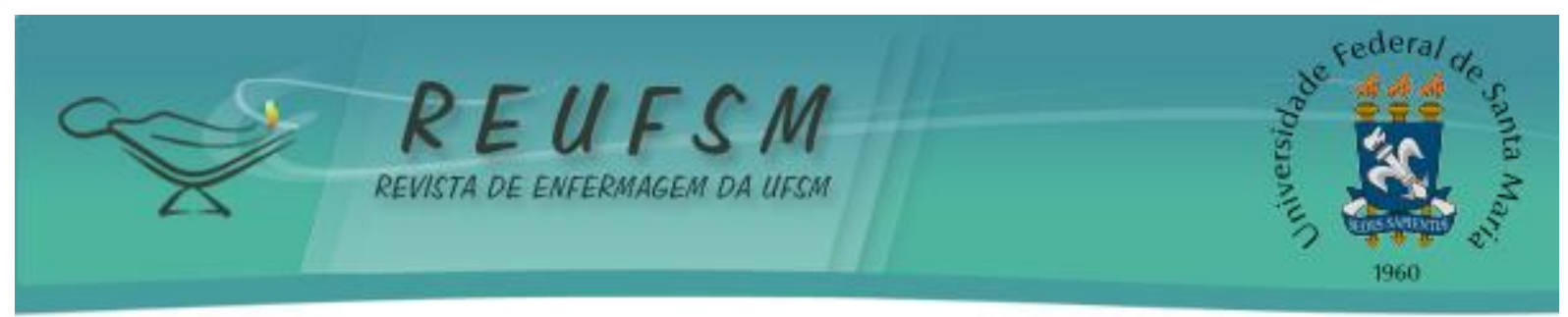

RESUMEN: Objetivo: comprender la participación de la familia durante la trayectoria de la enfermedad de cáncer de mama. Método: estudio descriptivo de enfoque cualitativo, realizado con siete miembros de dos familias que sufrieron de la enfermedad. El instrumento de recolección de datos fue una entrevista semi-estructurada. Se utilizó el análisis de contenido temático para el procesamiento y análisis de datos.Resultados: considerando el Marco Teórico de la Constelación Modelo Enfermedad los datos fueron organizados en cuatro categorías: estádio de la incertidumbre, estádio de la ruptura, luchando por recuperar el self y recuperando el bienestar. Consideraciones finales: el estudio permitió ampliar el conocimiento y la comprensión de la participación familiar frente la enfermedad de cáncer de mama basado en un modelo teórico específico.

Descriptores: Familia; Neoplasias; Enfermedades crónicas; Enfermería; Neoplasias de la mama.

\section{INTRODUÇÃO}

O câncer da mama é o tipo de neoplasia que mais acomete as mulheres em todo o mundo $^{1}$ e a cada ano se evidencia o aumento de sua incidência em todas as regiões brasileiras. ${ }^{2}$ Diante dessas projeções, pode-se vislumbrar o número de famílias e de pessoas que serão impactadas por esse diagnóstico. Nessa perspectiva, a mulher diagnosticada com câncer de mama necessitará de cuidados, atenção e apoio, tendo na unidade familiar o principal suporte para o enfrentamento da doença.

A família, além de oferecer conforto afetivo e emocional, compartilha responsabilidades nas decisões tomadas, acompanha e facilita os caminhos a serem percorridos na busca do diagnóstico e do tratamento. Contudo, considerando a indissociabilidade dos efeitos positivos e negativos que o adoecimento pode causar, possíveis modificações na maneira dos membros da família pensarem, sentirem e agirem influenciarão no comportamento individual e na dinâmica familiar a depender de suas crenças e sua cultura. ${ }^{3-4}$ A definição de família, elaborada para este estudo, é concebida como um grupo que se identifica como tal, composto por pessoas que, unidas por vínculos biológicos, afetivos ou por afinidade, tem senso de pertencimento, comprometem-se umas com as outras e compartilham valores, crenças, conhecimentos e práticas. ${ }^{5-7}$

Diante do adoecimento por câncer as famílias convivem com a ambiguidade ao perceberem que o sofrimento imposto pelo tratamento se constitui na única possibilidade de cura e que diante da realidade a vontade da pessoa doente, em muitos momentos, é desistir. ${ }^{8-9}$ Esse contexto complexo e tenso potencializa o desgaste físico, o estresse e a ansiedade da doente e de seus familiares. ${ }^{9}$ Estudos apontam que mudanças ocorrem na vida das famílias diante de uma experiência de adoecimento por câncer, principalmente de ordem existencial e relacional. ${ }^{3-4,7-10}$ Considerando as repercussões da experiência do adoecimento no núcleo familiar, destaca-se que a família, como interlocutora e partícipe nesse processo, também necessita ser incluída no planejamento da assistência de enfermagem..$^{8-9}$

O suporte oferecido pela família à mulher com câncer pode encorajar, estimular e fortalecer, favorecendo um ajustamento saudável à nova condição de saúde. A acolhida, o reconhecimento e a reconfiguração do papel da mulher dentro do núcleo familiar são componentes essenciais à sua recuperação ou reabilitação. ${ }^{12} 0$ apoio emocional e informativo, advindo principalmente dos familiares, potencializa a capacidade da mulher em gerir sua doença, favorecendo o bem estar e as habilidades para lidar com sua condição. ${ }^{13}$

Frente a esse cenário, a mulher e seus familiares vivenciam um processo relacional em que, mutuamente, influenciam e são influenciados, podendo interferir e até 


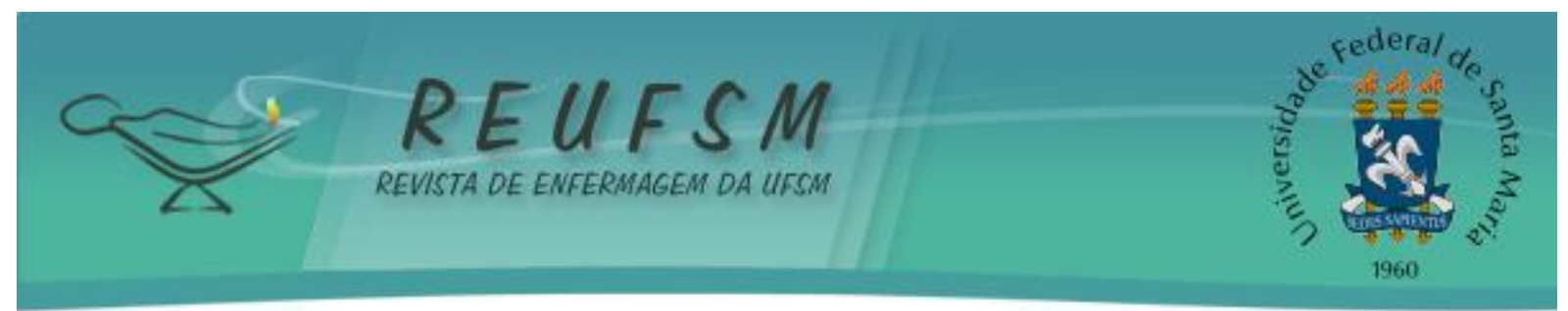

transformar o estilo de vida familiar, ocasionar mudanças nos papeis de cada membro e demandar esforço para definir e manter o seu funcionamento. ${ }^{3,14}$ Assim, reconhecendo que estratégias e ações individuais, interpessoais e/ou coletivas são exigidas dos membros da família diante de cada etapa do processo de adoecimento por câncer, entende-se que a enfermagem, ao se aproximar dessa dimensão da experiência familiar, poderá oferecer um cuidado compreensivo e singular.

0 presente estudo tem como pergunta de pesquisa: Como a família participa diante da trajetória do adoecimento de uma familiar por câncer de mama? O objetivo é compreender a participação da família no decorrer da trajetória do adoecimento por câncer de mama.

\section{MÉTODO}

Trata-se de um estudo descritivo, de abordagem qualitativa, realizado com sete pessoas integrantes de duas famílias que vivenciaram o adoecimento por câncer de mama de uma familiar, incluindo a pessoa que adoeceu. A amostra foi definida por intencionalidade, a partir de dados obtidos em uma Unidade Básica de Saúde. Foram critérios de inclusão o fato de que a pessoa doente já tivesse concluído o tratamento oncológico, que os familiares fossem maiores de 18 anos e tivessem convivido com a pessoa diagnosticada no decorrer da doença e que todos os participantes soubessem do diagnóstico do câncer de mama. E como critério de exclusão se definiu pessoas com dificuldade cognitiva que prejudicasse a comunicação verbal e a interpretação das perguntas.

O local da investigação foi um município na região noroeste do Estado do Rio Grande do Sul (RS), Brasil. A coleta dos dados ocorreu nos meses de março e abril de 2010 por meio de entrevistas semiestruturadas, audiogravadas e, posteriormente, transcritas. As perguntas direcionadas à mulher/mãe foram: Fale-me como foi seu adoecimento desde o início? E para sua família, como foi isso? Como foi a convivência familiar nesse tempo? As perguntas direcionadas aos familiares foram: Conte-me como foi o adoecimento da... (nome)? Como foi para você e sua família esse tempo? Como foi a convivência familiar durante o adoecimento da...? Os dados foram coletados com cada membro da família individualmente, em visita domiciliar. As entrevistas duraram de 30 a 90 minutos.

$\mathrm{Na}$ análise dos dados se adotou como referencial teórico o Modelo de Constelação da Doença, o qual foi desenvolvido por Morse e Johnson para compreensão da trajetória da doença crônica. ${ }^{15}$ Este Modelo possibilita uma visão compreensiva das experiências vivenciadas pelo indivíduo doente e seus familiares, uma vez que considera que a doença crônica afeta a todos que convivem com a pessoa doente, desde o surgimento de sinais e sintomas e da suspeita, até a recuperação ou assunção de si, envolvendo a perspectiva do indivíduo e, também, dos familiares que convivem, percebem as alterações e se envolvem no decorrer do processo patológico. ${ }^{15}$

O Modelo divide a experiência da doença em quatro estágios: Estágio da incerteza: ocorre quando o doente e sua família suspeitam de que algo de grave esteja acontecendo; Estágio da ruptura: é um estágio permeado pela crise que se inicia no momento no qual o diagnóstico é confirmado e o doente e a família decidem procurar por ajuda; Esforçando-se para recuperar o self: caracteriza-se pelo comprometimento da família com a luta da pessoa doente, dando suporte e assistência, e ela, por sua vez, luta para fazer com que a doença tenha sentido; e Recuperando o bem estar: inicia-se no momento em que a pessoa doente alcança o domínio ao recuperar as relações antigas e controle do self, e a família "busca o fim", reconhecendo e monitorando os sintomas do doente e vivendo dentro dos novos limites que a doença estabelece. ${ }^{15}$ 


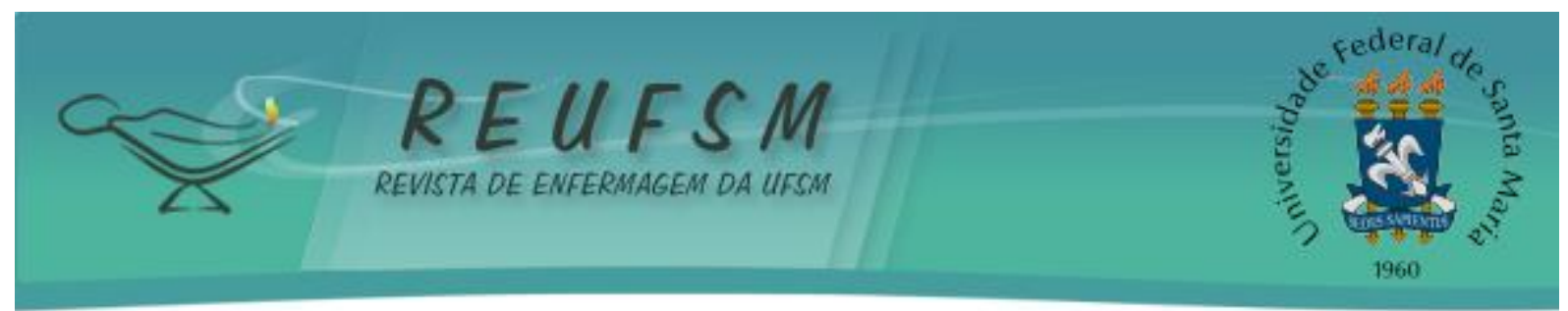

Entende-se por self a noção de "eu", as características, atributos, qualidades e defeitos, capacidades e limites, valores e relações que o indivíduo reconhece em si e percebe como parte integrante de sua identidade. É como a pessoa se identifica e como se percebe na realidade. ${ }^{15}$

Nessa perspectiva, a análise dos dados seguiu a técnica da análise de conteúdo temática. ${ }^{16}$ Assim, o conteúdo das entrevistas foi agrupado, por convergência de ideias, em categorias temáticas definidas de acordo com os diferentes estágios apresentados na trajetória da doença que compõe o Modelo Teórico. 0 estudo foi desenvolvido após a aprovação do Comitê de Ética em Pesquisa (CEP), da Universidade Regional do Noroeste do Estado do Rio Grande do Sul com parecer $n^{\circ} 133 / 2010$, e foram seguidos os preceitos éticos da Resolução 196/96, que envolve pesquisas com seres humanos e estava vigente na época da coleta dos dados. Todos os participantes assinaram o Termo de Consentimento Livre e Esclarecido e, como garantia de anonimato, foram identificados pela letra $E$, de entrevistado, seguida de um número sequencial e da letra inicial que identifica a posição dos participantes do estudo ("M" para a mulher com câncer de mama, "E" para esposo, "F" para filha/o e "N" para nora).

\section{RESULTADOS E DISCUSSÃO}

\section{Caracterização dos participantes do estudo}

Os participantes do estudo foram sete pessoas, integrantes de duas famílias, sendo duas mulheres/mães com diagnóstico de câncer de mama, com 41 e 81 anos respectivamente, uma casada e a outra viúva, que realizaram mastectomia parcial e controle anual da doença; um esposo de 50 anos, agricultor; duas filhas, uma com 19 e a outra com 39 anos, uma solteira e outra casada; um filho de 36 anos, casado e uma nora de 29 anos, casada.

As categorias referentes aos quatro estágios da experiência da doença do Modelo de Constelação da Doença ${ }^{15}$ são apresentadas e discutidas a seguir.

\section{O estágio da incerteza}

A experiência da doença começa quando o indivíduo se percebe suspeitando de que algo está acontecendo de modo anormal com seu corpo, e ele se depara com a incerteza sobre sua condição de saúde.

Eu estava sentada com uma freira na igreja. Passei a mão no meu seio e senti um caroço. Assustei-me! A freira falou: o que foi? Eu disse: senti uma coisa no meu seio, tipo um caroço. Ela achou que eu estava brincando, mas viu que eu estava com cara de apavorada. (E5-M)

Ficou tipo um machucadinho. Era estranho, falei para meu marido. Ele falou que eu devia procurar um médico na cidade, pra ver o que era, mas eu achava que não era nada. (E1-M)

No momento em que sente a alteração na mama, a mulher é tomada pelo sentimento da incerteza, pelo medo de estar doente por câncer e pela descrença que isso possa corresponder à verdade. A ambiguidade de sentimentos resulta de mecanismos de proteção, que tentam negar a possibilidade de estar doente como forma de aliviar a 


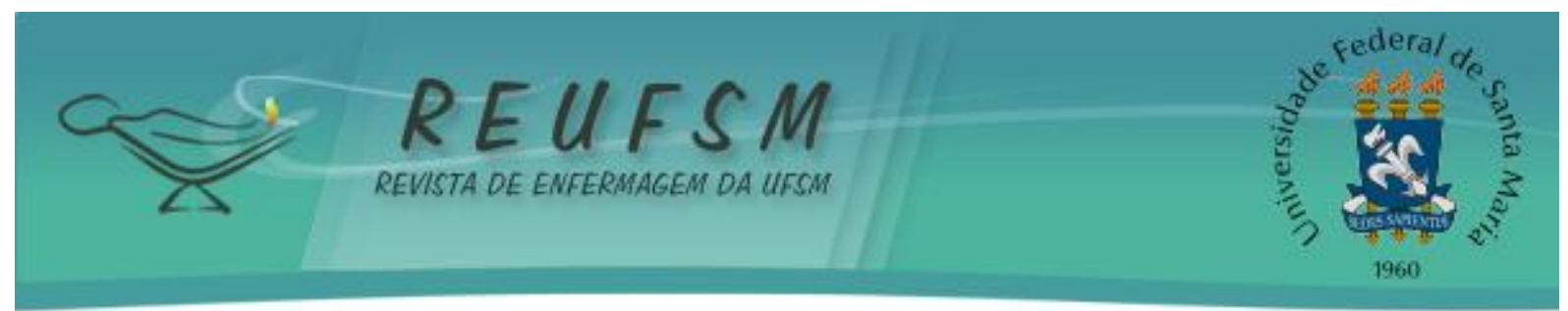

ansiedade, ao invés de considerar o perigo. ${ }^{12,17}$ As suposições que, automaticamente, vão sendo elaboradas e o sentimento de angústia e pavor que surge são características desse momento vivido de modo singular e ao tempo de cada mulher. ${ }^{18-19}$

No caso específico do câncer de mama, os familiares passam a suspeitar da doença a partir do momento em que a mulher conta a eles sobre o que percebeu de diferente em sua mama. Diante da revelação, eles ficam desconfiados e começam a avaliar o que pode significar essas alterações, passando a exercer um monitoramento sobre a situação.

Quando nós a enxergávamos, sempre perguntávamos se estava bem, se tinha sumido o machucado, se estava com dor. (E3-F)

No processo de monitorar a evolução dos sintomas, a família também vivencia incertezas e temores. No entanto, procura não evidenciá-los como forma de proteger a mulher, evitando seu sofrimento. ${ }^{7}$ Ao perceber que não há melhora no sintoma, a família acaba sendo subjugada pela situação. ${ }^{15}$ Assim, procuram intervir para que alguma atitude seja tomada, reforçam a necessidade de buscar ajuda profissional e tentam convencer a mulher que esta medida se faz necessária para esclarecer as dúvidas.

Como levar essa mulher no médico? Foram dias de teimosias até ela aceitar. Foi uma briga só. (E6-E)

Ela não queria ir ao médico! De tanto eu implorar e conversar... A freira também insistiu. Aí ela foi. (E7-F)

Ao admitir que as alterações possam ser decorrentes de uma doença, a mulher e sua família passam a vivenciar uma nova fase: a da confirmação do diagnóstico e da busca do tratamento.

\section{O estágio da ruptura}

Este estágio é caracterizado pela aceitação, por parte da mulher, de que a doença é real, e pela busca de ajuda especializada, sendo o diagnóstico, então, confirmado.

Resolvi ir ao médico, ver logo o que era isso! Ele me examinou e sentiu o caroço. Mandou fazer a mamografia. Veio o resultado e fui fazer uma biópsia. Meu marido e minha filha estavam juntos comigo. Daí veio o diagnóstico, era câncer mesmo. Parece que tudo desabou em minha cabeça. (E5-M)

A partir da constatação da doença, uma situação de crise se instala individualmente e na unidade familiar. Os membros da família se dão conta da desorganização da dinâmica familiar ante a presença da doença ${ }^{15}$ e buscam se reorganizar, fazendo ajustes para atender às necessidades da mulher. Diante da perspectiva de mudanças necessárias, os familiares aceitam responsabilidades, comprometendo a sua rotina para ajudar no cuidado.

Para ajudá-la tive que parar meu trabalho, deixar minha filha, que era pequena, com meu marido. Ele teve que dar conta de todo o trabalho sozinho e ainda preocupado comigo. Eu nem conhecia a 


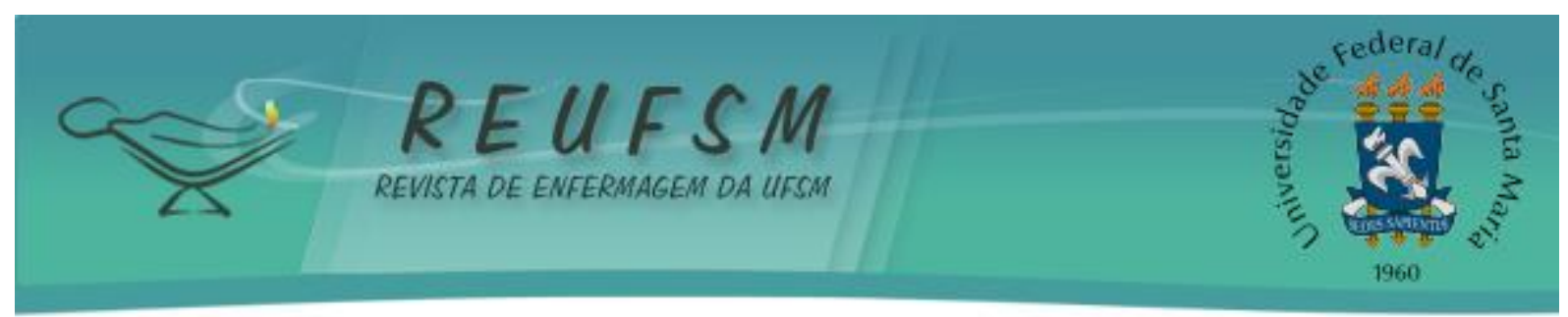

cidade. Peguei o ônibus e fui perguntando, desde que desci na rodoviária. (E2-F)

Aos poucos as mulheres vão deixando que os familiares tomem as decisões e façam as atividades por elas e, assim, vão se distanciando de si. Esse período é permeado pela crise frente ao desconhecido e pela renúncia do controle que emerge na situação; o distanciamento do seu mundo; e a dependência da família e dos profissionais da saúde, mesmo que por um limitado período de tempo. ${ }^{14}$

No começo eu não queria aceitar ajuda nenhuma, eles tinham a vida deles e eu tinha que trabalhar. Quando eu fiz a cirurgia e a quimioterapia não tive como negar a ajuda deles. Eu não tinha forças, precisava ajuda para tomar banho, comer, me vestir, e eu já não me importava mais, tanto fazia. (E1-M)

O "estar com câncer" pode trazer implicações físicas, emocionais, afetivas, profissionais e financeiras para a pessoa enferma, comprometendo as relações familiares, gerando ansiedade, tensão e conflito. A busca por solução recai no sistema de cuidado familiar, o qual acessa recursos que nem sempre são efetivos, mas que podem ajudar a aumentar o sentimento de segurança e bem estar. ${ }^{13}$

O impacto do adoecimento provoca mudanças no comportamento e no cotidiano das pessoas envolvidas, instaurando um processo doloroso de rupturas e reconstituição no decorrer dos estágios. ${ }^{15} \mathrm{~A}$ instabilidade emocional pode variar a cada estágio da doença, não raro, dando lugar a sentimentos de desamparo e emoções que incluem o medo, a ansiedade, a tristeza e o desânimo. ${ }^{20}$

A família, então, assume um perfil de vigilante, protetora e reguladora emocional, ajudando e cuidando para que a doente não se preocupe, não realize esforços físicos, se preserve dos afazeres domésticos, e orientando no autocuidado. ${ }^{4}$ Os familiares tomam para si o compromisso de assumir responsabilidades no tratamento da mulher, incentivando-a para que aceite as intervenções necessárias na terapêutica, e preservando seu bem estar.

Tínhamos que ficar vigiando, senão ela escapava para fazer algum serviço. Imagina, a gente ficava preocupada! $E$ na época da quimioterapia, então! Sabíamos que ela passava mal e toda vez eu ficava aflita, pensando que ela ia passar mal, essas coisas, mas ela sempre se mostrou forte. (E3-F)

O papel da família, expresso nas diversas formas de cuidado, torna-se fundamental para a mulher, enquanto realiza o tratamento. Esta relação se firma pelo apoio, pela solidariedade e por estar presente para encorajar e incentivar a se manter confiante. Assim, a fragilidade ou fortificação dos laços familiares serão influenciadas pelas condutas da família, podendo esta ser capaz de superar as dificuldades ou se deixar abater por elas. ${ }^{19}$

\section{Esforçando-se para recuperar o self}

Neste estágio da doença, o indivíduo se esforça para recuperar seu bem estar, analisa sua doença fazendo com que ela tenha sentido, renegocia papéis e promove seu autocontrole, buscando recuperar a confiança. ${ }^{15}$ Ao tentar compreender o sentido da doença, a mulher busca explicações que possam justificá-la. Algumas percebem o 


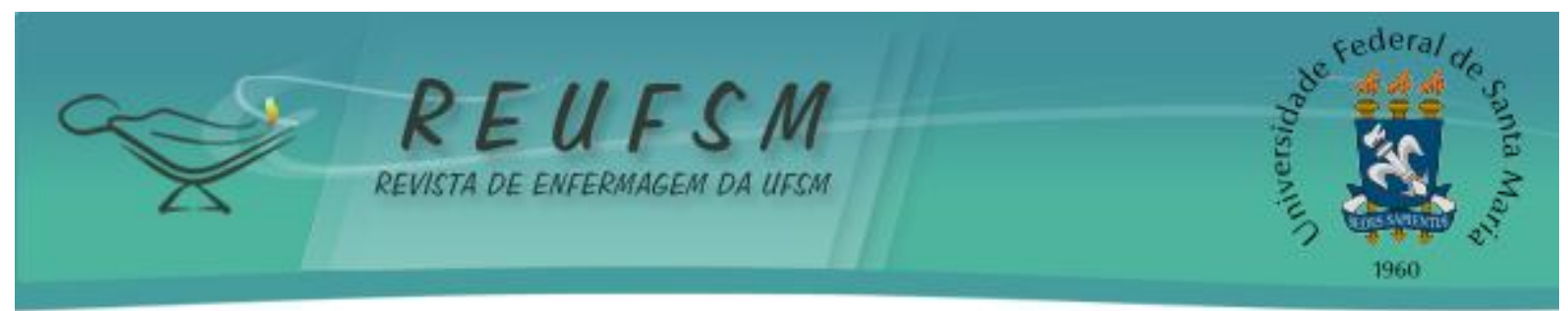

adoecimento como uma provação, a vontade de Deus ou um castigo por algo errado que tenham feito no passado e que estão, atualmente, "pagando" por isso.

Pensei muitas vezes quando estava doente, que tinha que ser uma provação minha ter que passar por tudo isso. Talvez para pagar alguma coisa de errado que fiz em minha vida, sei lá, a vontade de Deus. (E1-M)

O desejo de se recuperar, contudo, contribui para que as mulheres colaborem no cuidado, aceitando a ajuda oferecida pelos familiares; procurando restringir as atividades, embora isso as faça se sentirem incapacitadas; e se esforçando para aceitar o tratamento e seus efeitos colaterais como necessários. Preservar o self é importante para se recuperarem.

Eu sabia que também precisava colaborar para ficar boa logo, me cuidando, aceitando a ajuda que estavam me dando. Muitas vezes me sentia uma inválida, mas com o tempo percebi que era só uma fase, que ia passar e eu poderia voltar fazer o que fazia antes, $e$ sabia que o meu velho dependia de mim. Quando tinha que fazer quimioterapia ficava pensando que era para meu bem, que precisava fazer. Na primeira vez vi umas mulheres sem cabelo. Fiquei pensando no meu cabelo que ia cair, mas era para meu bem. E cabelo nasce de novo! Era preciso fazer! (E1-M)

Ao se empenhar para resgatar o controle de si e da situação e dar sentido à experiência, pode ocorrer momentos de insegurança e medo, diante das incertezas relacionadas ao adoecimento e ao futuro. $\mathrm{Na}$ experiência de conviver com o câncer de mama a mulher se sente impotente, frágil e, muitas vezes, inútil, tanto em relação às tarefas mais simples até às mais complexas, desejando não ser dependente. Reconhecendo-se em situação de vulnerabilidade e necessitando de ajuda, a mulher vive um sofrimento moral e psicológico, mais do que físico. ${ }^{21}$

Ao perceber a fragilidade, a família oferece suporte por meio de comentários incentivadores, solicitações para que mantenha a força e a coragem, elogios com a finalidade de transmitir confiança, aumentar a autoestima e amenizaras angústias no que se refere aos problemas financeiros.

O importante é saber enfrentar e dar força para quem precisa, ter muita coragem. Minha mãe não queria demonstrar medo, tristeza. Tinha vez que ela não conseguia segurar, e aí eu brincava: cadê aquela mulher forte, a mais forte que eu já vi? Aí ela sorria e mudava seu ânimo. (E2-F)

À medida que a mulher se esforça para recuperar o self e restitui, aos poucos, sua independência novamente, ela retoma o fazer de tarefas básicas da vida diária, sendo permitida pela família, a princípio, a realização das atividades mais simples, que necessitam de menor dispêndio físico e menor planejamento cognitivo. ${ }^{22}$

Tanto o doente quanto a família se empenham para voltar à vida normal, sendo flexíveis às mudanças de papéis, desempenhando as tarefas esperadas, em especial as de fornecer apoio e proteção. ${ }^{9}$ 


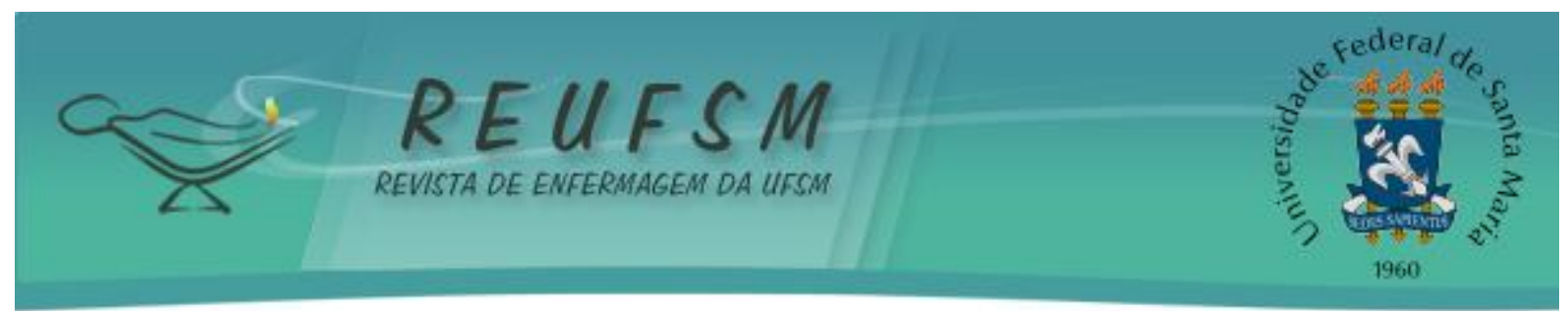

Recuperando o bem estar

No estágio final da trajetória, o indivíduo busca recuperar os relacionamentos anteriores, assumindo responsabilidades, alcançando o domínio, a autonomia, deixando a doença para trás, e controlando seu self. ${ }^{15}$ Para isso, à medida que percebe sua melhora, busca reassumir suas responsabilidades, retornando às suas atividades, porém reconhecendo e respeitando seus limites.

Eu queria fazer de novo as coisas que eu fazia, ter o meu espaço. Precisava disso para continuar vivendo. Sei que não sou aquela pessoa que era antes, estou mais fragilizada. Mas a vida continua, não posso olhar para trás. (E5-M)

Ao sentir que está bem, a mulher desempenha suas atividades de forma cuidadosa, a fim de não comprometer sua saúde, agora recuperada. Esse processo de retorno ao trabalho é vigiado pelos membros da família como uma forma de cuidado e proteção.

Sei que foi difícil. Nós somos pobres, temos que trabalhar e eles deixavam de fazer as coisas para cuidar de mim. Por isso, quando percebi que estava com condição de começar a ajudar, comecei. la fazendo como podia. Mostrava-me forte para eles não brigarem comigo, e quando brigavam, eu ria dizendo: eu que sou mãe de vocês! São vocês quem devem me obedecer! Minha família percebeu que eu podia voltar quase à minha vida normal. (E1-M)

Os familiares percebem que as mulheres vão reestabelecendo seu antigo padrão de vida, reassumindo o trabalho e seu papel familiar. Compreendem que a vida da família se redefine novamente, com possibilidade de reorganização da rotina e com uma nova visão de futuro. Então, gradativamente, os familiares renunciam ao controle e vão se afastando.

Ela pegou uma empregada, mas fazia o serviço igual. Voltou à vida normal, e nós também. Deixei de fazer o serviço da casa dela e meu marido podia estar em casa comigo, tendo nossa vida. (E4-N)

Nossa convivência mudou muito, eu e minha mãe sempre fomos muito amigas, mas parece que ficamos mais unidas. Meu pai começou valorizar a família, dar importância à mãe. (E7-F)

O orgulho e a satisfação da família e da mulher em saber que juntos conseguiram superar a trajetória do adoecimento e recuperar a saúde, e que as mudanças também serviram para melhorar a relação familiar, possibilita o retorno à vida normal e os deixa mais unidos e confiantes.

No último estágio, a tarefa principal da mulher e da família se relaciona à busca pela estabilidade, a aprender a viver na nova condição de vida imposta pela doença, reconhecendo suas limitações, identificando e monitorizando as sinalizações do corpo, até ser considerada curada. Tanto o doente como os familiares buscam retornar à vida que tinham antes do adoecimento. Assim, a reestruturação de suas existências ocorre em 


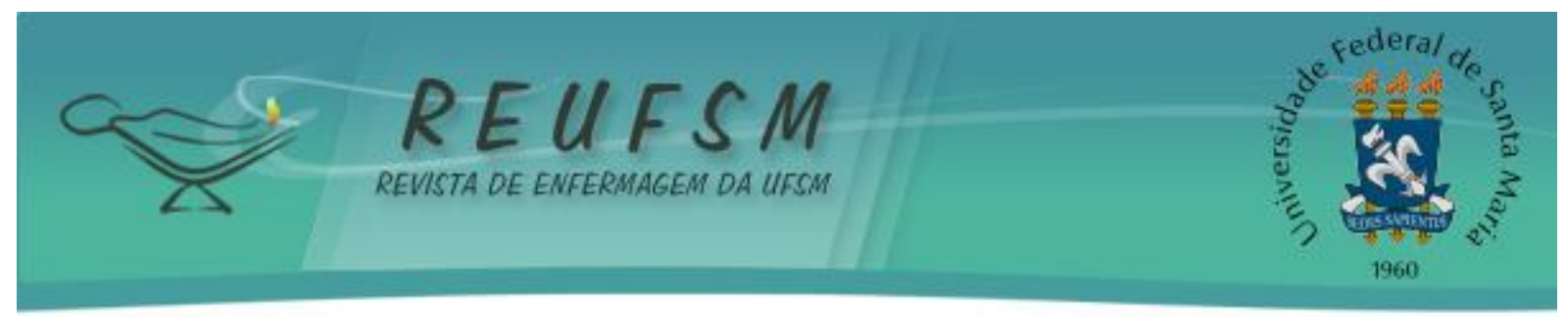

função da enfermidade, de seu significado social e das consequentes dificuldades que surgem com a mesma, demarcando o último estágio. ${ }^{12}$

\section{CONCLUSÃO}

A utilização do referencial teórico Modelo de Constelação da Doença possibilitou a apreensão dos movimentos familiares empreendidos no decorrer da trajetória do adoecimento de uma familiar por câncer de mama, evidenciando que a participação da família é ativa, cooperativa e modulada pelas necessidades da mulher com diagnóstico de câncer de mama em cada fase da experiência vivida.

Nesse sentido, o impacto do adoecimento por câncer de mama promove mudanças no cotidiano e no comportamento familiar, constituindo-se em um processo de transição em que a família e a pessoa doente vão, gradativamente, aceitando que diante da circunstância vivida cada um precisará, ao mesmo tempo, ceder espaço e ocupar o espaço cedido. A mulher necessita de tempo para a realização do tratamento, para cuidar de si e para se permitir ser cuidada, abrindo mão de outras atividades e, muitas vezes, do controle da situação.

Os familiares, por sua vez, precisam se disponibilizar para a assunção de novas tarefas e responsabilidades, cuidar, tomar decisões e, quando possível, distanciar-se, permitindo que a mulher retome o controle de sua vida e o seu papel na família. Embora a vida familiar se estabilize e retorne a um padrão de normalidade, o cuidado vigilante se torna constante na nova rotina, zelando pela manutenção do bom estado de saúde da mulher.

A compreensão, por parte dos enfermeiros, sobre o modo como a família - pessoa doente e seus familiares - se movimenta no decorrer da trajetória do adoecimento tem implicações para o cuidado dela, podendo ajudar no planejamento de intervenções adequadas a ela. É importante destacar que as famílias participantes deste estudo finalizaram o tratamento oncológico obtendo a cura da doença, o que, de certa forma, evidencia uma experiência singular.

Diante do contexto apresentado, este estudo amplia o conhecimento e a compreensão acerca do adoecimento por câncer de mama, da pessoa doente e de seus familiares, com base em um modelo específico, o qual oferece recursos teóricos para qualificar o cuidado direcionando-o às necessidades da família e indicando novos caminhos para outros estudos através de suas práticas.

Contudo, cabe destacar que os resultados do estudo se encontram nos limites de uma amostra restrita a duas famílias, nas quais as mulheres conseguiram concluir com sucesso o tratamento oncológico, podendo ser consideradas sobreviventes do câncer de mama. Nesse sentido, a realização de estudos com famílias em diferentes fases do adoecimento, bem como com outras patologias, podem contribuir para evidenciar a utilidade do Modelo de Constelação da Doença para a compreensão da trajetória familiar diante do adoecimento.

\section{REFERÊNCIAS}

1. Fonseca SM, Pereira SR. Enfermagem em oncologia. São Paulo: Atheneu; 2013.

2. Instituto Nacional do Câncer (INCA). Coordenação Geral de Ações Estratégicas. Coordenação de Prevenção e Vigilância. Estimativa 2014: incidência de câncer no Brasil. Rio de Janeiro: Inca; 2014. 


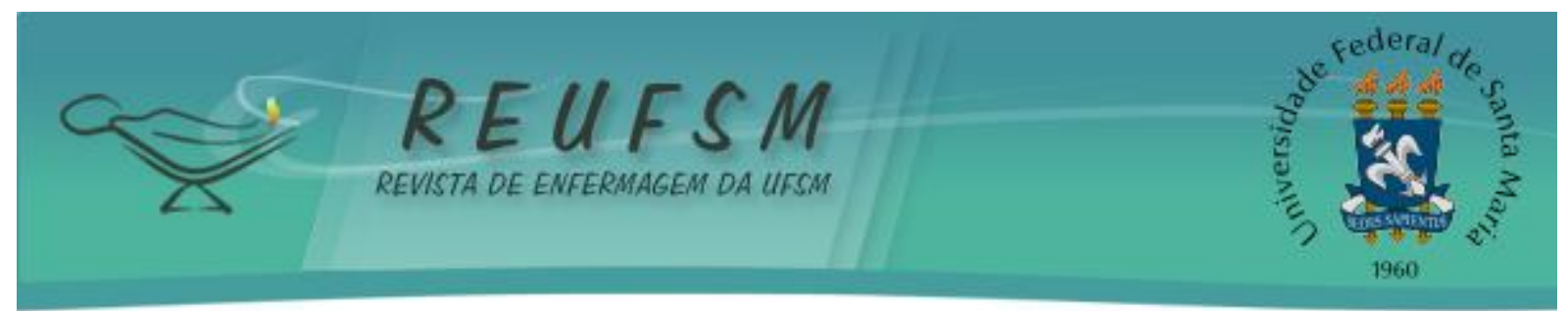

3. Duggleby W, Bally J, Cooper D, Doell H, Thomas R. Engaging hope: the experiences of male spouses of women with breast cancer. OncolNursForum [Internet]. 2012 [acesso em 2015 jan 15];39(4):400-6. Disponível em: https://onf.ons.org/onf/39/4/engaging-hopeexperiences-male-spouses-women-breast-cancer.

4. Kissil K, Niño A, Ingram M, Davey M. "I knew from day one that i'm either gonna fight this thing or be defeated": africanamerican parents' experiences of coping with breast cancer. J FamNurs [Internet]. 2014 [acesso em $2016 \mathrm{fev}$ 23];20(1):98-119. Disponível em: http://jfn.sagepub.com/content/20/1/98.full.pdf+html.

5. Wright LM, Leahey M. Enfermeiras e famílias: guia para avaliação e intervenção na família. $6^{\text {a }}$ ed. São Paulo: Roca; 2015.

6. Biroli F. Família: novos conceitos. São Paulo: Editora Fundação Perseu Abramo; 2014.

7. Bertoldo C, Girardon-Perlini NMO. A trajetória de uma família no adoecimento e morte de um familiar por câncer: compromisso e solidariedade. Rev Contexto Saúde. 2007;7(12):49-58.

8. Sales CA, Matos PCB, Mendonça DPR, Marcon SS. Cuidar de um familiar com câncer: o impacto no cotidiano de vida do cuidador. Rev Eletrônica Enferm [Internet]. 2010 [acesso em 2013 ago 14];12(4):616-21. Disponível em: http://www.fen.ufg.br/fen_revista/v12/n4/pdf/v12n4a04.pdf.

9. Melo MCB, Barros EM, Campello MCVA, Ferreira LQL, Rocha LLC, Silva CIMG, et al. O funcionamento familiar do paciente com câncer. PsicolRev [Internet]. 2012 [acesso em 2016 jan 15];18(1):78-89. Disponível em: http://pepsic.bvsalud.org/pdf/per/v18n1/v18n1a07.pdf.

10. Ferreira DB, Farago PM, Reis PED, Funghetto SS. Nossa vida após o câncer de mama: percepções e repercussões sob o olhar do casal. Rev Bras Enferm. 2011;64(3): 536-44.

11. Timm AMB, Beuter M, Girardon-Perlini NMO, Schwartz E, Budó MLD, Pauletto MR. A dinâmica da família frente à diálise peritoneal no domicílio. RevEnferm UFSM [Internet]. 2015 [acesso em 2015 dez 20];5(3):511-20. Disponível em: http://periodicos.ufsm.br/reufsm/article/view/16632.

12. Ramos WSR, Sousa FS, Santos TR, Silva Júnior WR, França ISX, Figueiredo GCAL. Sentimentos vivenciados por mulheres acometidas por câncer de mama. J Health Scilnst [Internet]. 2012 [acesso em 2013 dez 20];30(3):241-8. Disponível em: http://www.unip.br/comunicacao/publicacoes/ics/edicoes/2012/03_julset/V30_n3_2012_p241a248.pdf.

13. Suwankhong $D$, Liamputtong $P$. Social support and women living with breast cancer in the south of Thailand. J NursScholarsh [Internet]. 2016 [acesso em $2016 \mathrm{fev}$ 23];48(1):3947. Disponível em: http://onlinelibrary.wiley.com/doi/10.1111/jnu.12179/epdf.

14. Nascimento AN, Castro DS, Amorim MHC, Bicudo SDS. Estratégias de enfrentamento de familiares de mulheres acometidas por câncer de mama. CiêncCuid Saúde [Internet]. 2011 [acesso em 2013 dez 20];10(4):789-4. Disponível em: http://www.periodicos.uem.br/ojs/index.php/CiencCuidSaude/article/view/18324/df.

15. Morse JM, Johnson JL. Towards a theory of illness: the illness constellation model. In: Morse JM, Johnson JL. The illness experience: dimensions of suffering. Newbury Park: Sage; 1991. Cap7, p. 315-42.

16. Minayo MCS. O desafio do conhecimento: pesquisa qualitativa em saúde. $12^{a}$ ed. São Paulo: Hucitec; 2014. 


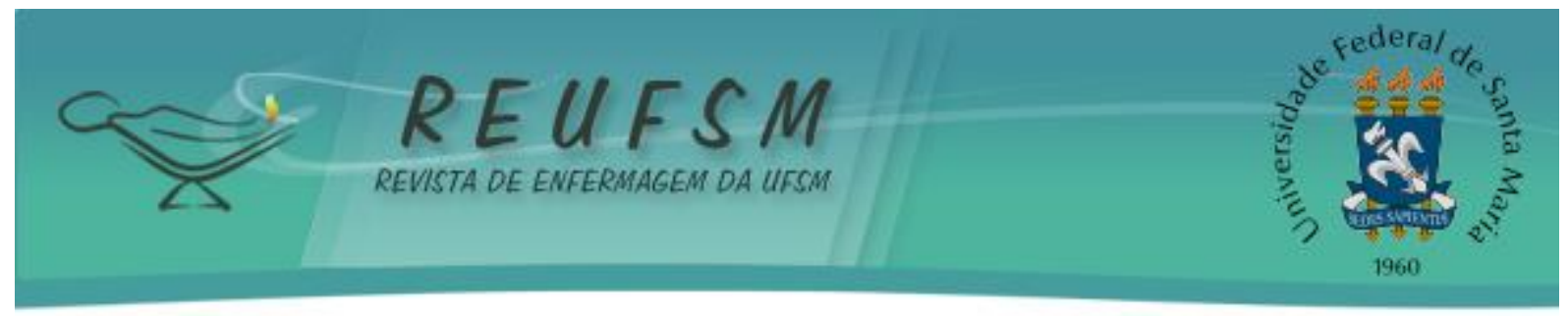

17. Rastad H, Khanjani N, Khandani BK. Causes of delay in seeking treatment in breast cancer patients in Iran: a qualitative content analysis study. AsianPac J CancerPrev [Internet]. 2012 [acesso em 2013 dez 20];13(9):4511-5. Disponível em: http://www.apocpcontrol.org/page/apjcp_issues_view.php?sid=Entrez:PubMed\&id=pmid:2 $3167370 \& k e y=2012.13 .9 .4511$.

18. Paiva ACPC, Salimena AMO, Souza IEO, Melo MCSC. Significado do diagnóstico de neoplasia mamária: compreensão fenomenológica de mulheres. Rev Baiana Enferm [Internet]. 2015 [acesso em 2016 fev 23];29(1): 59-67. Disponível em: http://www.portalseer.ufba.br/index.php/enfermagem/article/view/12239/9543.

19. Feijó AM, Schwartz E, Jardim VMR, Linck CL, Zillmer JGV, Lange C. O papel da família sob a ótica da mulher acometida por câncer de mama. CiêncCuid Saúde [Internet]. 2009 [acesso em 2013 dez 20];8 Supl:79-84. Disponível em: http://www.periodicos.uem.br/ojs/index.php/CiencCuidSaude/article/view/9721/5534.

20. Sprung BR, Janotha BL, Steckel AJ. The lived experience of breast cancer patients and couple distress.J AmAcad Nurse Pract [Internet]. 2011 [acesso em 2015 dez 20];23(11):61927. Disponível em: http://onlinelibrary.wiley.com/doi/10.1111/j.17457599.2011.00653.x/pdf.

21. Rosa LM, Radünz V. Significado do câncer de mama na percepção da mulher: do sintoma ao tratamento. RevEnferm UERJ [Internet]. 2012 [acesso em 2016 jan 15]; 20(4):445-50. Disponível em: http://www.facenf.uerj.br/v20n4/v20n4a06.pdf.

22. Fangel LMV, Panobianco MS, Kebbe LM, Almeida AM, Gozzo TO. Qualidade de vida e desempenho de atividades cotidianas após tratamento das neoplasias mamárias. Acta Paul Enferm [Internet]. 2013 [acesso em 2013 dez 19];26(1):93-100. Disponível em: http: / / www.scielo.br/scielo.php?pid=S0103-21002013000100015\&script=sci_arttext.

Data de recebimento: $26 / 12 / 2015$

Data de aceite:12/07/2016

Contato do autor responsável: Nara Marilene O. Girardon-Perlini

Endereço postal: Av. Roraima, 1000. Prédio 26. Sala 1339. Cidade Universitária. Santa Maria RS. CEP: $97105-900$

E-mail: nara.girardon@gmail.com 